\title{
Pronoun disambiguation: Accessing potential antecedents
}

\author{
ALBERT T. CORBETT \\ University of South Carolina, Columbia, South Carolina 29208 \\ and \\ FREDERICK R. CHANG \\ University of Oregon, Eugene, Oregon 97403
}

\begin{abstract}
Two general classes of pronoun disambiguation processes are considered. In reading "Jack threw a snowball at Phil, but he missed," both possible antecedents of "he" ("Jack" and "Phil") may be accessed initially. Or, the actual antecedent alone may be accessed after sufficient semantic context is encoded. To evaluate these alternatives, a yes-no-probe recognition task was used to measure priming of the potential antecedents in sentence comprehension. Subjects read sentences similar to the example and were presented a test word immediately following each sentence. Response times for the actual antecedent ("Jack") and nonantecedent ("Phil") probes were obtained. Results indicated that the nonantecedent as well as the antecedent was activated (accessed) in pronoun disambiguation. This conclusion was not affected by the ordering of the antecedent and nonantecedent in the first clause.
\end{abstract}

Identifying the antecedent (referent) of a pronoun in text is a complicated inferential process. The pronoun specifies semantic constraints that can be used as retrieval cues to identify the antecedent (e.g., the antecedent of "she" must be feminine). However, these semantic constraints on the antecedent are often insufficient to uniquely identify the antecedent (as in the sentence "Alice stole the basketball from Cathy, and then she sank a jumpshot"). To disambiguate a pronoun, therefore, it is generally necessary to encode the clause containing the pronoun and to integrate semantic and syntactic information in that clause with earlier clauses in the text (Caramazza, Grober, Garvey, \& Yates, 1977; Garvey, Caramazza, \& Yates, 1976; Hirst \& Brill, 1980; Sheldon, 1974). The present paper examines the relationship between these two processes: retrieval of potential antecedents (with a pronoun as a retrieval cue) and the use of clausal context to select the actual antecedent.

Consider the sentence "Scott stole the basketball from Warren and then he sank a jumpshot." The pronoun "he" in the second clause is ambiguous, since two men are mentioned in the first clause, but the reference can be disambiguated semantically. The present paper

This research was supported by National Institute of Education Grants NIE-G-77-0008 and NIE-G-80-0175. We would like to thank Randy Engle, Barbara Dosher, Chuck Clifton, and two anonymous reviewers for comments on earlier drafts of this paper. Requests for reprints should be sent to Albert T. Corbett, Department of Psychology, University of South Carolina, Columbia, South Carolina 29208. F. R. Chang is now at Bell Laboratories, Whippany, New Jersey. considers two general models of this pronoun assignment process. One alternative, a unique-access model, suggests that semantic context will be employed to uniquely access the intended antecedent ("Scott") in memory. Other potential referents ("Warren") will not be accessed during the pronoun assignment process. This alternative assumes that the clause containing the pronoun is encoded prior to pronoun assignment, and the information in the two clauses is integrated to uniquely specify the antecedent. Since the semantic constraints imposed by a pronoun are logically insufficient to identify the antecedent, this could be a reasonable ordering of the two processes.

An alternative, the multiple-access model, would suggest that when a pronoun is encountered in a text, it is employed as a cue to retrieve any potential antecedents in memory. Although a pronoun does not provide logically sufficient information to uniquely identify the antecedent, the information may be pragmatically sufficient if the retrieval process is restricted. In particular, the search may be restricted to text constituents that are highly available in memory. Several studies of pronouns and anaphoric nouns have demonstrated that an antecedent is more available when it appears in the clause immediately preceding the reference, rather than earlier in the text (Carpenter \& Just, 1977a; Clark \& Sengul, 1979; Hupet \& Le Bouedec, 1977; Lesgold, Roth, \& Curtis, 1979). Antecedents are also more available when they have otherwise been "foregrounded" in the text (Carpenter \& Just, 1977a; Lesgold et al., 1979; Sanford \& Garrod, 1981, pp. 134-145). If the retrieval process were restricted to these highly available 
text components, that process might often yield a single potential antecedent. The preliminary identification of this likely antecedent could then facilitate encoding of the remainder of the clause.

The present set of studies employed a probe recognition task to compare the unique-access and multipleaccess models. During each trial of this task, subjects read a sentence that was immediately followed by a test word. Subjects were instructed to decide as quickly as possible whether the test word had appeared in the sentence. Previous research in sentence memory has indicated that time to recognize a memory probe is speeded if the corresponding concept has been activated (McKoon \& Ratcliff, 1979, 1980b, 1981; Ratcliff \& McKoon, 1978). Thus, we can employ this task to determine what concepts have been activated in processing a pronoun. Studies by Chang (1980) and McKoon and Ratcliff (1980a) have already begun to do this and have shown that the presence of an anaphoric reference (a pronoun or an anaphoric category noun) in the final clause of a text speeds probe response time for the antecedent noun in the text. For example, Chang presented sentences such as "Mary and Bill went to the store and he bought a quart of milk," and showed that response time to the test probe "Bill" (the antecedent of the pronoun in the second clause) was shorter than response time to "Mary" (a nonantecedent). McKoon and Ratcliff presented four-sentence paragraphs followed by a probe word. They found that response time for a word that had appeared in the first sentence (e.g., "burglar") was speeded when it was the antecedent of a fourth-sentence category noun (e.g., "The criminal slipped away from the street lamp"), compared to a control condition that did not refer to the burglar (e.g., "The cat slipped away from the street lamp"). Thus a noun that has been directly referenced with a pronoun or category noun in the final clause of the passage is more available in an immediate probe recognition task than is a noun that has not been so referenced.

The present studies employed a similar design, in which subjects read two-clause sentences with an anaphoric reference in the second clause (e.g., "Ellen aimed a pistol at Harriet, but she did not pull the trigger"). The first clause contained two proper names, one of which was the antecedent of the pronoun ("Ellen") the other being a nonantecedent name of the same sex ("Harriet"). The second-clause anaphoric reference was either a pronoun or a repetition of the proper name (e.g., "Ellen aimed a pistol at Harriet, but Ellen did not pull the trigger"). Immediately following the sentence, a probe word was presented (e.g., "Ellen" or "Harriet"), and subjects were asked to decide if the word appeared in the sentence. We expected to replicate Chang's (1980) findings concerning the antecedent ("Ellen"). That is, we expected subjects to confirm that "Ellen" appeared in the sentence more quickly than they would confirm that "Harriet" appeared, because there is a reference to "Ellen" in the second clause, but no reference to
"Harriet." (Regardless of how the anaphoric reference is disambiguated, we expected the actual antecedent to be more available at the end of the second clause.) However, we were more interested in comparing response time for the nonantecedent ("Harriet") in the proper name and pronoun conditions. For the conditions in which the second clause contains a proper name reference ("Ellen"), we did not expect the nonantecedent ("Harriet") to be accessed in second clause processing; thus the proper name condition served as a control condition. If the nonantecedent is accessed in pronoun processing, as the multiple-access model predicts, then nonantecedent response times should be shorter in the pronoun condition than in the proper name condition. If the nonantecedent is not accessed in processing the second clause, as the unique-access model predicts, then no difference should result in nonantecedent probe reaction time (RT) across the two conditions.

\section{EXPERIMENT 1}

This study examined the activation of the actual antecedent and a second potential antecedent for three types of anaphoric references. In addition to a proper name reference and pronoun reference, we examined an elliptical construction, in which there is no surface subject in the second clause (e.g., "Ellen aimed a pistol at Harriet, but did not pull the trigger"). This reference can be disambiguated syntactically, since the elliptical second-clause subject must refer to the first-clause subject. Thus, if a constituent in memory can be readily accessed according to its syntactic role, we would not expect the nonantecedent second-clause object to be activated by the reference. In this case, results should be similar in the proper name and elliptical conditions. However, if syntactic role does not provide as effective a retrieval cue as the proper name reference, then we may again find evidence of an antecedent search that also activates the nonantecedent first-clause object. Hirst and Brill (1980) also examined syntactic constraints in processing anaphoric reference and found that a similar, though weaker, constraint was not used by subjects to limit the retrieval process.

Following each probe recognition response, a comprehension question was presented to determine whether the subject had correctly identified the antecedent of the anaphoric reference. Thus, we can restrict our examination of the activation of antecedents and nonantecedents to those trials in which the reader has correctly processed the second-clause anaphoric reference.

\section{Method}

Subjects. Twenty-four undergraduates participated in this experiment and were paid $\$ 2.50$ for a session that lasted $1 \mathrm{~h}$.

Materials and Design. Six test conditions were formed by crossing three sentence types with two probe types. Each test sentence consisted of two main clauses conjoined by "and" or "but." The subject of the second clause was always anaphoric, 
and the antecedent was always the first-clause subject. Two proper names appeared in each sentence; one always appeared as the first-clause subject (the antecedent), and the other (the nonantecedent) appeared in the predicate of the first clause, either as the object or in a prepositional phrase, or it appeared in a subordinate clause conjoined with the first-clause predicatc. (The name in this position will be referred to as the "predicate name" in further discussion.) The three versions of each sentence were generated by varying the form of the anaphoric second-clause subject. In one version, a proper name was employed (e.g., "Karen poured a drink for Emily and then Karen put the bottle down"). In the second, a pronoun was employed ("Karen poured a drink for Emily and then she put the bottle down"), and in the third condition, an elliptical construction was employed ("Karen poured a drink for Emily and then put the bottle down"). Test sentences were generated so that the antecedent of the second-clause anaphoric reference could be disambiguated semantically. The nonantecedent proper name that appeared in the first clause ("Emily") was not explicitly referenced in the second clause. The sentences employed in the study are listed in Appendix A.

Each of the three sentence types was followed half the time by an antecedent (first-clause subject) recognition probe ("Karen") and the other half by a nonantecedent (predicate name) probe ("Emily"). We expected recognition response time to be shorter when the probed constituent is activated in the second clause of the sentence as well as the first (Chang, 1980 McKoon \& Ratcliff, 1980a). Therefore, if the nonantecedent is, in fact, accessed in processing a pronoun or elliptical structure (but not in processing a proper name), then response time for the nonantecedent probe ("Emily") should be shorter following a pronoun, or elliptical structure, than following a second-clause proper name.

The experimental sessions consisted of 72 test trials, 12 per condition, intermixed with 132 distractor trials, all preceded by 8 practice trials. Seventy-two sentence frames were generated for the test trials and randomly assigned positions in the stimulus sequence, as were the distractors. Six stimulus lists were then constructed so that each of the 72 sentence frames appeared once in each test condition across the lists (the position of the test sentence frames and distractors in each list was constant). Each subject was presented one of the lists. In rotating the sentences through the conditions, the subject and object names were manipulated so that the probe word remained constant.

A two-alternative forced-choice comprehension question followed the probe recognition response and tested the secondclause subject (e.g., "Who put the bottle down?") to assess whether the readers had correctly encoded the antecedent. Thus, the two alternatives for this forced-choice question were always the two names that appeared in the first clause. Each alternative (right or left) was correct for half the trials in each condition. The alternatives were manipulated so that the correct response remained on the same side for a given test sentence across all six lists.

There were a variety of distractor types. Fifty-four were identical in form to the test sentences. (Each second-clause subject type, proper name, pronoun, and elliptical, appeared in one-third of the sentences.) Twenty-four of these were followed by false person probes (these probes had appeared in earlier trials), and 30 probed nonhumans (half true, half false). Twothirds of the comprehension questions tested nonhuman alternatives, and one-third tested humans. Approximately threequarters of these questions tested the first clause.

An additional 48 distractors also consisted of two clauses, but the second-clause subject was coreferential with the proper name that appeared in the first-clause predicate [e.g., "John tossed an orange to Bill but (Bill/he) missed it"l. Half contained a second-clause proper name and the other half contained a pronoun. Half the probes were true and half were false. Crossed with this, half the probes were human and half were nonhumans. Again, two-thirds of the comprehension questions tested nonhuman alternatives and three-quarters tested the first clause.

The remaining 30 distractors were selected from magazines. All varied from the two-clause structure of the other sentences, and none contained a proper first name. Again, half the probes were true and half were false.

Procedure. On each trial, subjects read a single sentence, one word at a time, at a self-paced rate. Immediately following the last word in the sentence, subjects made a probe recognition decision and then responded to a comprehension question. The experiment was controlled by a PDP-15 computer, and stimuli were presented on a CRT display. A three-key keyboard was used to record responses. Subjects controlled word presentation rate with their thumbs on the middle key and pressed the adjacent keys with their index fingers to respond in the probe recognition and comprehension tasks.

At the beginning of each trial, READY appeared on the screen. The subject pressed the thumb key when ready to proceed, and the first word in the sentence immediately appeared. Subjects pressed the key again for the next word, and so on. Lach succeeding word appeared in the same position on the screen, while the preceding word was erased. When the thumb key was pressed following the last word in the sentence, a probe word appeared immediately in a larger type size and in a different position on the screen. Subjects decided as quickly as possible whether the probe word had appeared in the sentence and responded with the appropriate index finger. A 500-msec blank interval followed this response, then a two-alternative forced-choice comprehension question was presented on the screen. Again, subjects made a decision and pressed the corresponding key as quickly as possible. Immediately following the comprehension question, feedback concerning response time and accuracy on the comprehension question was presented for $2 \mathrm{sec}$. A 1-sec blank interval followed this feedback, and then the next trial began. There were a total of 212 trials in the experiment.

\section{Results and Discussion}

Recognition probes. The probe recognition task was used to assess activation of a nonantecedent when an anaphoric reference is correctly processed. Therefore, the probe recognition analysis excluded trials in which the comprehension response was incorrect or comprehension RT exceeded the subject's mean by at least 5 standard deviations (recall that in test trials the comprehension question always tested the antecedent of the second-clause subject). In addition, probe response times more than 5 standard deviations above the subject's overall mean were excluded. Table 1 displays the

Table 1

Response Time in Milliseconds (Correct Responses) and Accuracy in the Probe Recognition Task, Experiment 1

\begin{tabular}{|c|c|c|c|c|}
\hline \multirow{3}{*}{$\begin{array}{c}\text { Second-Clause } \\
\text { Subject }\end{array}$} & \multicolumn{4}{|c|}{ Probe Type } \\
\hline & \multicolumn{2}{|c|}{$\begin{array}{c}\text { Antecedent } \\
\text { (First-Clause } \\
\text { Subject) }\end{array}$} & \multicolumn{2}{|c|}{$\begin{array}{c}\text { Nonantecedent } \\
\text { (First-Clause } \\
\text { Predicate) }\end{array}$} \\
\hline & $\mathrm{RT}$ & $\mathrm{PC}$ & RT & $\mathrm{PC}$ \\
\hline Proper Name & 813 & 100 & 1081 & 90 \\
\hline Pronoun & 871 & 98 & 999 & 95 \\
\hline Elliptical & 867 & 94 & 952 & 93 \\
\hline
\end{tabular}

Note $\cdots P C=$ percent correct. 
resulting mean response times for correct probe responses, along with percent correct in each test condition.

RTs for these correct probe responses were submitted to an analysis of variance. Separate analyses were performed treating subjects as a random variable (collapsing across stimuli) and treating stimuli as a random variable (collapsing across subjects). In these and all other analyses in this paper, min $\mathrm{F}^{\prime}$ (Clark, 1973) is reported when significant. Otherwise, F1 (subjects as a random factor) and F2 (stimuli as a random factor) are reported separately. Analyses of the probe response times in Table 1 revealed a significant main effect of probe type $\left[\min F^{\prime}(1,85)=19.27, p<.001\right]$. Responses were $161 \mathrm{msec}$ faster and error rates lower when the antecedent first-clause subject was probed than when the nonantecedent first-clause predicate name was probed $(850 \mathrm{msec}$ vs. $1,011 \mathrm{msec})$. The main effect of secondclause subject type (proper name, pronoun, or elliptical) was nonsignificant. In addition, the interaction of probe type and second-clause subject type, which may provide evidence of nonantecedent activation, was significant $\left[\min F^{\prime}(2,146)=4.09, p<.05\right]$. As Table 1 reveals, the effect of probe type (antecedent or nonantecedent) was smaller in the pronoun and elliptical conditions than in the proper name condition.

We are primarily interested in response time to the nonantecedent probe for each of the three types of anaphoric reference. When the second clause contains a proper name anaphoric reference (e.g., "Karen"), we do not expect a nonantecedent (e.g., "Emily") to be accessed. However, if the nonantecedent is accessed in processing a second-clause pronoun of the appropriate gender ("she"), then we would expect the nonantecedent to be more available in the probe task. In this case, we would expect response time for a nonantecedent probe to be faster in the pronoun than in the proper name condition. If the nonantecedent is not accessed in processing a pronoun, then we expect no difference between the proper name and pronoun conditions. As can be seen in Table 1, response time to the nonantecedent probe is $82 \mathrm{msec}$ faster in the pronoun than in the proper name condition, and a planned comparison revealed that this difference is significant $\left[\min F^{\prime}(1,83)=4.88, p<.05\right]$. In addition, evidence was obtained that the nonantecedent was accessed in processing the elliptical second-clause subject construction. Responses to nonantecedent probes were $129 \mathrm{msec}$ faster following an elliptical subject than following a proper name. This difference was significant in a planned comparison $\left[\min F^{\prime}(1,73)=5.06, p<.05\right]$. The readers apparently did not use the syntactic information to uniquely access the intended antecedent, a result that is consistent with Hirst and Brill (1980). While syntactic information is generally lost quite rapidly from memory, it is not necessarily lost after 2 or $3 \mathrm{sec}$, which is the approximate interval between the first-clause subject and second-clause subject in this study (Anderson \& Paulson, 1977; Begg \& Wickelgren, 1974; Sachs, 1967, 1974). Nevertheless, surface structure role does not appear to serve as an effective retrieval cue to limit the search for potential antecedents. The difference in response times between the pronoun and elliptical conditions for nonantecedent probes was nonsignificant and, in any case, represents a speedaccuracy tradeoff.

Finally, with respect to the antecedent first-clause subject probes, a small "name-match" effect was obtained, but the effect was nonsignificant. That is, probe response time was faster following a proper name (the same word as the probe) than following a pronoun or elliptical construction. But a planned comparison of the first condition vs. the mean of the remaining two conditions did not reach significance.

Accuracy rates in the probe recognition task were also submitted to an analysis of variance, and the results paralleled those of the RT data. Responses were more accurate for antecedent probes than for nonantecedent probes (97\% vs. $93 \%$ ), and this difference was significant $\left[\min F^{\prime}(1,67)=5.62, p<.05\right]$. The effect of subject type was nonsignificant, but the interaction of the two main effects was significant $[F 1(2,46)=2.82$, n.s.; $F 2(2,142)=6.11, p<.01]$. Again, the difference in accuracy between the antecedent and nonantecedent conditions was greater in the proper name condition (in which the antecedent name actually appeared in the second clause) than in the pronoun or elliptical conditions.

We have provided evidence that the nonantecedent probes are processed faster following a second-clause pronoun or elliptical reference than following a secondclause proper name, and we have argued that comprehension of the pronoun and elliptical construction results in activation of the nonantecedent. An alternative explanation, however, may be considered. Reading a proper name in the second clause may actually suppress the other proper name from the first clause. Such suppression would result in increased latency and error rate in responding to a nonantecedent probe. In other words, responses to nonantecedent probes may be faster following a second-clause pronoun rather than a proper name because of inhibition in the proper name condition rather than facilitation in the pronoun condition. There is evidence from previous probe recognition studies, however, that appears to contradict this interpretation.

As described earlier, Chang's (1980) study was similar to the present ones, except that the two proper names in the first clause differed in gender (e.g., "Mary and Bill went to the store and he bought a quart of milk"). The second-clause subject was either a proper name or pronoun reference to one of the two individuals (i.e., "Bill" or "he"). Since the second-clause pronoun and nonantecedent name differ in gender in Chang's study, we would not expect the nonantecedent to be accessed in pronoun processing. As a result, we would not expect 
probe RT for the nonantecedent to vary across the proper name and pronoun conditions. On the other hand, the proper name inhibition hypothesis would suggest that response time to the nonantecedent would be slower in the proper name condition. Chang's results are presented in Table 2. As can be seen, response time for a nonantecedent probe ("Mary") was constant across the proper name and pronoun condition ( $775 \mathrm{msec}$ vs. $777 \mathrm{msec}$ ). Thus, a proper name in the second clause did not interfere any more than a pronoun did with access to the other proper name in the first clause. Evidence from a probe recognition study by Burrows and Okada (1976) is inconsistent with the further possibility that interference is restricted to proper names of the same category (gender). Burrows and Okada employed word lists rather than sentences as the memory set in their study. They varied set size, and for set size greater than one, they varied whether the words in a list all came from the same category or each came from separate categories. For each set size, RT was virtually identical for the two types of lists. If examples from the same category mutually interfered with each other, longer RTs would be expected in the homogeneous condition. The lack of an interference effect in these studies suggests that the effect in the present study is not an inhibitory one.

Comprehension questions. Trials in which comprehension response times were more than 5 standard deviations above the subject's grand mean were excluded from the analysis. Response times and accuracy levels are displayed in Table 3.

Table 2

Probe Recognition Time in Milliseconds (Correct Responses) and Accuracy in Experiment 2 of Chang (1980)

\begin{tabular}{cccccc}
\hline & \multicolumn{4}{c}{ Probe Type } \\
\cline { 2 - 3 } \cline { 5 - 6 } Second-Clause & \multicolumn{2}{c}{ Antecedent } & & \multicolumn{2}{c}{ Nonantecedent } \\
\cline { 2 - 5 } Subject & RT & PC & & RT & PC \\
\hline Proper Name & 694 & 98 & 775 & 95 \\
Pronoun & 743 & 98 & 777 & 95 \\
\hline
\end{tabular}

Note $-P C=$ percent correct .

Table 3

Response Time in Milliseconds (Correct Responses) and Accuracy for the Comprehension Questions, Experiment 1

\begin{tabular}{|c|c|c|c|c|}
\hline \multirow{3}{*}{$\begin{array}{l}\text { Second-Clause } \\
\text { Subject }\end{array}$} & \multicolumn{4}{|c|}{ Probe Type } \\
\hline & \multicolumn{2}{|c|}{$\begin{array}{c}\text { Antecedent } \\
\text { (First-Clause } \\
\text { Subject) }\end{array}$} & \multicolumn{2}{|c|}{$\begin{array}{l}\text { Nonantecedent } \\
\text { (First-Clause } \\
\text { Predicate) }\end{array}$} \\
\hline & $\mathrm{RT}$ & PC & RT & PC \\
\hline Proper Name & 1800 & 89 & 1846 & 85 \\
\hline Pronoun & 1853 & 80 & 1950 & 76 \\
\hline Elliptical & 1876 & 83 & 1920 & 81 \\
\hline
\end{tabular}

Note-PC= percent correct.
As might be expected, there was a trend for longer RTs and lower accuracy in the pronoun and elliptical conditions than in the proper name condition. Analyses of variance revealed that this main effect of surface subject was significant for error rates $\left[\min \mathrm{F}^{\prime}(2,144)=4.41\right.$, $p<.05]$, but not response times. The main effect of probe type and the interaction were nonsignificant in both the accuracy and response time analysis, although there was a tendency for a first-clause predicate name probe to interfere in both measures.

Subjects did not comprehend the pronoun or elliptical clauses as accurately as the proper name sentences. This suggests that the reading time data, to be reviewed next, will almost certainly underestimate the time required to comprehend the pronoun and elliptical constructions, relative to the proper name condition.

Reading times. Five measures of second-clause reading time were calculated to compare proper name and pronoun encoding. These measures were (1) the secondclause subject alone, (2) the word following the secondclause subject, (3) the final word in the clause, (4) the penultimate word in the clause, and (5) average reading time for all words in the second clause excluding the subject. This last analysis revealed that the overall mean reading time for the second clause (excluding the subject) was $380 \mathrm{msec} /$ word. However, the five analyses were surprisingly insensitive to the proper name/pronoun distinction. Only one analysis, the second one, revealed a significant effect of second-clause subject type. Surprisingly, subjects were actually $15 \mathrm{msec}$ faster in the pronoun condition than in proper name condition in this analysis $[\mathrm{F} 1(1,23)=5.03, \mathrm{p}<.05 ; \mathrm{F} 2(1,71)=1.00$, n.s.]. We expected reading times to be longer in the pronoun condition. However, the results could indicate that subjects recognized the ambiguity in the pronoun condition and accelerated their reading rate to obtain information necessary to resolve it. The analysis, of course, revealed no significant main effect of probe type or interaction with subject type (the probes were presented after subjects read the sentence). Two factors in this study may contribute to the insensitivity of reading time measures to the relative difficulty of pronoun processing. One, mentioned above, is that subjects did not process the sentences as thoroughly and accurately in the pronoun condition. Second, word-by-word reading times for single sentences may be limited by factors other than semantic processes (e.g., motor performance and perceptual processes).

\section{EXPERIMENT 2}

The results of Experiment 1 are inconsistent with a unique-access model of pronoun disambiguation. When a pronoun is encountered, the reader apparently does not finish encoding the clause and then use that information to access the intended antecedent alone. Instead, the results support a model in which all potential ante- 
cedents are accessed while an anaphoric reference is processed.

A second question we can raise concerns the nature of the access process. Given the test sentence structure in Experiment 1, the results are compatible with a form of "serial look-back" model. That is, the reader may encode the second clause prior to accessing antecedents and then check potential antecedents one at a time, beginning with the most recent, and working backward through the preceding clause(s) until an acceptable antecedent is encountered. Such a procedure, of course, would access a proper name in the predicate and reject it prior to accessing the first-clause subject. Springston (1975) provided evidence consistent with a serial lookback model, but in a fairly restricted situation in which one potential antecedent appeared in the same clause with the anaphoric reference and the other potential antecedent appeared in the preceding clause. In the present experiment, we examined the retrieval of two potential antecedents that both appear prior to the clause containing the anaphoric reference and, in fact, either appear in the same clause or in a pair of embedded clauses. To test this serial look-back model, the structure of the test sentences was modified. Sentences with two main clauses were again employed, but now the secondclause subject was coreferential with the proper name that appeared in the predicate [e.g., "Bonnie passed the basketball to Claire and (Claire/she) sank a jumpshot"). The serial look-back model would predict that the nonantecedent first-clause subject would not be accessed in processing the second-clause anaphoric reference.

\section{Method}

Subjects. Twenty undergraduates participated in this experiment and were paid $\$ 2.50$ for a session that lasted $1 \mathrm{~h}$.

Materials and Design. There were four test conditions (two sentence types by two probe types). The test sentences were structurally similar to those in Experiment 1, except that the second-clause subject referred to the first-clause predicate name (e.g., "Gary gave Kevin a lot of money and Kevin spent it foolishly"). Two versions of each test sentence frame were generated by varying the form of this second-clause subject (proper name or pronoun). Again, the test sentences were generated so that the actual antecedent of the second-clause subject could be identified semantically. There were two probe types, the antecedent first-clause predicate name ("Kevin") and the nonantecedent first-clause subject ("Gary"). The test sentences employed in Experiment 2 are listed in Appendix B.

Forty-eight test sentence frames were generated and employed to construct four stimulus lists by rotating the sentences through the four test conditions as in Experiment 1. Again, there were 12 trials/condition in each list. Each of the 48 sentence frames was randomly assigned to 1 of 180 positions in the stimulus sequence, and distractors were randomly assigned to the remaining 132 positions. These positions remained constant across the four stimulus lists. (These 180 trials were preceded by 8 practice trials representing various conditions.) Again, a comprehension question followed each probe recognition decision, and in the test trials, that question always tested the second clause agent (e.g., "Who spent the money foolishly?"). Each alternative (right or left) was correct half the time.

The 132 distractor trials were analogous to those in Experiment 1. Fifty-four consisted of sentences identical in form to the test sentences, 48 reversed the antecedent relationship (i.e., the first-clause subject was coreferential with the second-clause subject), and 30 distractors were natural sentences selected from magazines. Probe and comprehension questions were assigned to each of these sets as in Experiment 1.

Procedure. The procedure was identical to Experiment 1, except that each session consisted of only 188 trials.

\section{Results and Discussion}

Recognition Probes. The probe analysis excluded those trials in which the comprehension response was incorrect, or in which the comprehension RT or probe RT exceeded the subject's mean by 5 standard deviations. Mean probe response time (correct responses) and percent correct for the four test conditions are displayed in Table 4.

The results of this experiment appear to be different from the corresponding proper name and pronoun results of Experiment 1. Analyses of variance revealed that there is no longer a significant main effect of probe type (antecedent vs. nonantecedent probes) but there is now a significant effect of second-clause subject type (995 msec in the proper name condition vs. 1,086 in the pronoun condition) $[\mathrm{F} 1(1,19)=6.26, \mathrm{p}<.05$; $F 2(1,47)=4.11, p<.05]$. Table 4 reveals that there is, in fact, an interaction of probe and reference type, and that interaction is significant $[\mathrm{F} 1(1,19)=4.65, \mathrm{p}<.05$; $F 2(1,47)=3.17$, n.s.]. Paired comparisons reveal that the $185 \mathrm{msec}$ difference between the two antecedent probe conditions is significant $\left[\min \mathrm{F}^{\prime}(1,58)=5.51\right.$, $\mathrm{p}<.05]$. More important, however, response times in the nonantecedent probe condition showed virtually no effect of second-clause subject type $(1,054 \mathrm{msec}$ in the proper name condition vs. $1,051 \mathrm{msec}$ in the pronoun condition). That is, RT data provide no evidence that the nonantecedent was accessed in pronoun disambiguation.

On the surface, this result concerning nonantecedent probes appears to support the serial self-terminating model. However, an analysis of variance of the accuracy data yielded results that conflict with this conclusion. In the accuracy data, there was a main effect of probe type $(96 \%$ correct in the antecedent condition vs. $92 \%$ in the nonantecedent condition) $[\mathrm{F}(1,19)=6.62$, $\mathrm{p}<.05 ; \mathrm{F} 2(1,47)=8.28, \mathrm{p}<.01]$. Thus, as in Experi-

Table 4

Response Time in Milliseconds (Correct Responses) and Accuracy in the Probe Recognition Task, Experiment 2

\begin{tabular}{lcccc}
\hline & \multicolumn{3}{c}{ Probe Type } \\
\cline { 2 - 5 } & $\begin{array}{c}\text { Antecedent } \\
\text { (First-Clause } \\
\text { Second-Clause } \\
\text { Subject }\end{array}$ & \multicolumn{2}{c}{$\begin{array}{c}\text { Nonantecedent } \\
\text { (First-Clause } \\
\text { Subject) }\end{array}$} \\
\cline { 2 - 6 } \cline { 4 - 6 } & RT & PC & RT & PC \\
\hline Proper Name & 935 & 99 & 1054 & 88 \\
Pronoun & 1120 & 94 & 1051 & 96 \\
\hline
\end{tabular}

Note $-P C=$ percent correct . 
ment 1 , subjects showed superior performance in the antecedent probe condition. The effect of second-clause subject type was nonsignificant, but the interaction was significant $[F 1(1,19)=6.28, p<.05 ; F 2(1,47)=5.72$, $\mathrm{p}<.05]$. Most important, however, a paired comparison revealed that nonantecedent probes were signifcantly more accurate following a second-clause pronoun than following a proper name $[\mathrm{F} 1(1,19)=5.66, \mathrm{p}<.05$; $\mathrm{F} 2(1,47)=7.77, \mathrm{p}<.01]$. Thus, accuracy data indicate there is some facilitation in responding to a nonantecedent probe following a pronoun, although this facilitation is not evident in the RT data.

The absence of such a facilitation effect on nonantecedent probe response time and the surprisingly slow response time for antecedent probes following a pronoun reference may both reflect difficulty that our subjects had in processing the pronoun version of the test sentences. Our subjects appear to have been influenced by a "parallel function strategy" (Sheldon, 1974). In natural English, a second-clause pronoun is typically coreferential with the first-clause constituent that fills the parallel (same) syntactic role. This, of course, was not the case in the present study. (Indeed, Sheldon would label our sentences anomalous.) Springston (1975, Experiment 8) has, in fact, demonstrated that sentences are more difficult to read when the syntactic role of pronoun and antecedent mismatch. (Reading times were $10 \%$ higher in the mismatch condition, and subjects made more errors in identifying the antecedent.) Thus subjects in Experiment 2 may have found it difficult to process a second-clause subject pronoun coreferential with the first-clause predicate name. As a result, subjects may still have been processing the sentence when the probe word appeared, particularly if the subjects got into a rhythm of pressing the key while reading, and this may have artifactually inflated response times in the pronoun condition. This possibility is examined (and supported) in the following experiment.

Comprehension questions. Again, trials with response times more than 5 standard deviations above the subject's mean were excluded from the analysis. Response times and accuracy levels are displayed in Table 5. Accuracy rates are slightly lower and response times slightly slower than in the preceding experiment, as

Table 5

Response Time in Milliseconds (Correct Responses) and Accuracy for the Comprehension Questions, Experiment 2

\begin{tabular}{ccccc}
\hline & \multicolumn{3}{c}{ Probe Type } \\
\cline { 2 - 5 } & $\begin{array}{c}\text { Antecedent } \\
\text { (First-Clause } \\
\text { Predicate) }\end{array}$ & & $\begin{array}{c}\text { Nonantecedent } \\
\text { (First-Clause } \\
\text { Subject) }\end{array}$ \\
\cline { 2 - 6 } $\begin{array}{c}\text { Second-Clause } \\
\text { Subject }\end{array}$ & RT & PC & RT & PC \\
\hline Proper Name & 2008 & 79 & 2038 & 77 \\
Pronoun & 2213 & 72 & 2010 & 75 \\
\hline
\end{tabular}

Note $-P C=$ percent correct . might be expected if subjects find these test sentences more difficult. Analyses of variance performed on both the RT and accuracy data revealed only one significant effect. The interaction of probe type and subject type was significant in the response time data $[\mathrm{F} 1(1,19)=$ $4.78, \mathrm{p}<.05 ; \mathrm{F} 2(1,47)<1$, n.s.]. As can be seen, RTs are elevated in one cell of the table, but we do not know what significance to attach to this interaction.

Reading times. The five measures of second-clause reading time described in Experiment 1 were again calculated to compare the encoding of proper names and pronouns. The grand mean of the reading times in the second clause, excluding the subject, was $470 \mathrm{msec}$, or $90 \mathrm{msec}$ longer than in the preceding experiment, again indicating that subjects may have found the current test sentences more difficult. However, none of the five measures revealed a significant effect of secondclause subject type. Although we would expect the pronoun condition to be considerably more difficult to encode than the proper name conditions, the reading times do not reflect this difference.

\section{EXPERIMENT 3}

The preceding experiment obtained evidence that in processing a pronominal reference to a name in the first-clause predicate, the nonantecedent first-clause subject is also accessed. However, this evidence appeared in the probe recognition accuracy data, rather than in the response time data. That is, responses to the nonantecedent subject probe were more accurate, but no faster, following a second-clause pronoun than following a proper name. At the same time, the name-match effect on response times was considerably larger in Experiment 2 than in Experiment 1 (i.e., response times to the antecedent predicate probe were faster following a second-clause proper name). These results suggest that probe response times in the pronoun conditions may be artificially inflated in the preceding experiment; subjects may still have been processing the test sentence when the recognition probe was presented. (This could also apply to Experiment 1, although presumably to a lesser degree. If so, the magnitude of the nonantecedent priming effect is underestimated, in that experiment, and the nonsignificant "name-match" effect for antecedent probes is overestimated.) Experiment 3 attempted to reduce this carry-over effect by replicating Experiment 2, but with a clause-by-clause, rather than word-by-word, method of presentation. Since our subjects would know exactly how many main clauses were being presented per sentence (two), and since the subjects should not fall into any rhythm in pressing the thumb key while reading, this method should enable subjects to finish processing the sentence before pressing the key to obtain the probe.

\section{Method}

Subjects. Twenty-four undergraduates served as subjects in this experiment and were paid $\$ 2.50$ for a session that lasted $1 \mathrm{~h}$. 
Materials and Design. The stimulus lists were identical to those presented in Experiment 2. The 30 natural sentences did not all consist of two main clauses but were presented in two parts, as were the other sentences (and they were broken at a phrase or clause boundary).

Procedure. The procedure was the same as in the first two experiments, except for sentence presentation. When subjects pressed the thumb key following the warning signal, the entire first main clause (including any subordinate clause) was presented on the screen. Following the next thumb press, the first clause was replaced on the screen by the second main clause. The second clause was erased following the next thumb press, and the probe was presented.

\section{Results and Discussion}

Recognition probes. Trials were excluded from the probe analysis according to the same criteria applied in the prior experiments. Mean probe response time (correct responses) and accuracy are displayed in Table 6 . Analyses of variance of response time revealed no significant main effect of probe type or second-clause subject type, but the interaction of these two factors was significant $\left[\mathrm{min} \mathrm{F}^{\prime}(1,48)=4.77, \mathrm{p}<.05\right]$. As expected, the clause-by-clause presentation method reduced the size of the "name-match" effect for antecedent probes, but subjects still responded faster to an antecedent probe in the proper name condition (in which the antecedent name actually appeared in the second clause) than in the pronoun condition. A pairwise analysis indicated that this 99 -msec effect is significant $[\mathrm{F} 1(1,23)$ $=7.44, \mathrm{p}<.05 ; \mathrm{F} 2(1,47)=6.66, \mathrm{p}<.05]$. More impor . tant, response times for the nonantecedent probes were significantly faster following a pronoun than following a proper name, and this 63 -msec difference was significant $[\mathrm{F} 1(1,23)=4.93, \mathrm{p}<.05 ; \mathrm{F} 2(1,47)=1.70, \mathrm{n} . \mathrm{s}$. $]$. This result is consistent with the accuracy result of Experiment 2 and provides evidence that the nonantecedent first-clause subject is accessed during pronoun disambiguation. This evidence is not compatible with the serial, self-terminating look-back model. Instead, these results, in conjunction with those of Experiment 1, are consistent with a model in which both potential antecedents are accessed during pronoun disambiguation.

The accuracy data were also submitted to an analysis

Table 6

Response Time in Milliseconds (Correct Responses) and Accuracy in the Probe Recognition Task, Experiment 3

\begin{tabular}{|c|c|c|c|c|}
\hline \multirow{3}{*}{$\begin{array}{c}\text { Second-Clause } \\
\text { Subject }\end{array}$} & \multicolumn{4}{|c|}{ Probe Type } \\
\hline & \multicolumn{2}{|c|}{$\begin{array}{c}\text { Antecedent } \\
\text { (First-Clause } \\
\text { Predicate) }\end{array}$} & \multicolumn{2}{|c|}{$\begin{array}{c}\text { Nonantecedent } \\
\text { (First-Clause } \\
\text { Subject) } \\
\end{array}$} \\
\hline & RT & PC & RT & PC \\
\hline Proper Name & 1003 & 99 & 1050 & 91 \\
\hline Pronoun & 1102 & 95 & 987 & 94 \\
\hline
\end{tabular}

Note $-P C=$ percent correct . of variance, and a pattern was obtained similar to that in Experiment 2. There was no main effect of subject type (proper name vs. pronoun), but there was a main effect of probe type (97\% correct in the antecedent probe condition vs. $93 \%$ in the nonantecedent probe condition) $\left[\min \mathrm{F}^{\prime}(1,64)=6.06, \mathrm{p}<.05\right]$. The interaction was also significant $[F 1(1,23)=5.05, p<.05 ; F 2(1,47)$ $=5.30, \mathrm{p}<.05]$.

Comprehension questions. Trials with response times 5 standard deviations above the mean were excluded from the analysis. Response time and accuracy are displayed in Table 7. Response times are somewhat faster and accuracy somewhat higher than in the previous study, as would be expected if subjects were processing the sentences more carefully in reading. Analyses of variance of response time revealed a significant main effect of probe type $\left[\min \mathrm{F}^{\prime}(1,59)=6.01\right.$, $\mathrm{p}<.05]$. Comprehension responses were slower following an antecedent first-clause predicate name probe than following a nonantecedent first-clause subject probe $(2,054 \mathrm{msec}$ vs. $1,885 \mathrm{msec})$. A similar nonsignificant trend was obtained in the previous experiments for a slower comprehension response time following a predicate name probe. The main effect of subject type and interaction were nonsignificant. Analyses of variance of accuracy data revealed a significant main effect of second-clause subject type $[\mathrm{F} 1(1,23)=6.15, \mathrm{p}<.05$; $\mathrm{F} 2(1,47)=2.09$, n.s.]. Subjects were significantly less accurate in the pronoun condition. No other effects were significant in the accuracy analysis.

Reading times. Mean reading times were calculated for both the first and second clauses of the test sentences. The overall mean for the first clause was $2,172 \mathrm{msec}$, and that for the second clause was $1,744 \mathrm{msec}$. Once again, no significant effect of second-clause subject type on second-clause reading times was obtained. Mean read. ing time for proper name clauses was $1,756 \mathrm{msec}$, and that for pronoun clauses was $1,732 \mathrm{msec}$. Thus, while subjects seem to have read the sentences more carefully than in Experiment 2, no evidence of the relative difficulty of pronoun disambiguation is obtained in the reading time results.

Table 7

Response Time in Milliseconds (Correct Responses) and Accuracy for the Comprehension Questions, Experiment 3

\begin{tabular}{lcccc} 
& \multicolumn{3}{c}{ Probe Type } \\
\cline { 2 - 5 } & $\begin{array}{c}\text { Antecedent } \\
\text { (First-Clause } \\
\text { Second-Clause } \\
\text { Subject }\end{array}$ & & \multicolumn{2}{c}{$\begin{array}{c}\text { Nonantecedent } \\
\text { (First-Clause } \\
\text { Subject) }\end{array}$} \\
\cline { 2 - 3 } \cline { 5 - 6 } & RT & PC & RT & PC \\
\hline Proper Name & 1986 & 82 & 1927 & 86 \\
Pronoun & 2122 & 81 & 1843 & 79 \\
\hline
\end{tabular}

Note-PC = percent correct. 


\section{GENERAL DISCUSSION}

Evidence obtained in a probe recognition task indicates that when a pronoun appears in a text, any possible antecedents in the preceding clause will be accessed. The semantic context provided in the clauses does not appear to limit access only to the actual antecedent. Moreover, this access does not have the characteristics of a serial self-terminating search within the clause; rather, both potential antecedents in the present study were accessed, regardless of serial position.

One somewhat surprising result in this task was that recognition responses for antecedent probes were not uniformly faster than responses to nonantecedent probes. Even though the nonantecedent was accessed in pronoun processing, we still expected the antecedent to be more available at the end of the sentence, because of the additional processing required to integrate the actual antecedent with the rest of the second clause. In fact, antecedent probe responses were significantly faster than nonantecedent probe responses only in Experiment 1. (Responses were significantly more accurate in the antecedent condition of all three experiments, but in Experiment 3, there is actually a speed-accuracy tradeoff with a nonsignificant difference in RT.) This pattern of results suggests that the first-clause subjects are more available at the end of the sentences than the first-clause predicate names, aside from any effects of the anaphoric reference. Moreover, this result was obtained regardless of second-clause subject type (proper name or pronoun). In the proper name condition, antecedent probes actually were verified more quickly than nonantecedent probes, but this effect was three times larger when the antecedent was the first-clause subject (Experiment 1) than when it was in the predicate (Experiments 2 and 3). In the pronoun condition, responses were actually faster to the nonantecedent probes than to the antecedent probes when the nonantecedent was the first-clause subject (Experiments 2 and 3 ).

The fact that this effect of first-clause subject vs. predicate is observed in the proper name as well as the pronoun condition suggests that it does not simply reflect the greater difficulty in pronoun processing in the latter two experiments. Instead, the effect may reflect the different roles that subjects and predicates perform in language. For example, the subject is often employed to convey old or "given" information (Chafe, 1970, p. 211; Haviland \& Clark, 1974; Sanford \& Garrod, 1981, pp. 92-93). A related suggestion is that the subject functions as the "topic" of the sentence (that is, it is what the sentence is "about"), whereas the predicate serves as a comment on the subject (Sanford \& Garrod, 1981, p. 136). The latter distinction, in particular, might suggest that the reader will devote more attention to the subject than to predicate nouns while processing a sentence. The manipulations in this experiment, however, do not enable us to evaluate this possibility.
A related effect has been obtained by Purkiss (as described in Sanford \& Garrod, 1981). Purkiss measured reading time for sentences containing an anaphoric reference. In this study, she varied whether the antecedent served as the subject or the object of its clause. She found that even when the anaphoric reference actually repeated the antecedent noun, reading time for the anaphoric reference was shorter when the antecedent was a subject than when it was an object. (This was true regardless of whether one or three sentences intervened between the clause containing the antecedent and the clause containing the reference.) Again, it appears that subject of a sentence is more available for subsequent retrieval than is a noun in the predicate.

What can we conclude concerning the temporal relationship between pronoun assignment and clause encoding? Certainly, final pronoun assignment in the current experiment must follow encoding of the second clause and integration of the two clauses, even though the parallel function strategy allows for a preliminary (and sometimes incorrect) assignment. However, retrieval of potential antecedents may be initiated when the pronoun is encountered and may go on in parallel with clause integration. Hirst and Brill (1980) reached a similar conclusion that integration is accomplished during rather than prior to assignment. Under some circumstances, preliminary assignment may actually be accomplished prior to complete clause integration. Indeed, the sentences in Experiments 2 and 3 may be difficult because such preliminary assignment is being made. Tyler and Marslen-Wilson (1977) have provided evidence that is relevant to this point. They note that phrases such as "flying planes" and "broiling hens" are both syntactically and semantically ambiguous. The first phrase, for example, may refer either to the act of flying planes or to planes that are flying. However, this phrase can be disambiguated by the following verb (e.g., "Flying planes are dangerous") or by information in the preceding clause (e.g., "If you walk by the runway, flying planes can be dangerous"). Tyler and MarslenWilson demonstrated that when disambiguating information is provided in the preceding clause, the reader begins selecting a meaning for the two-word ambiguous phrase before encoding the remainder of the clause. That is, when the reference "flying planes" is encountered, the reader begins retrieving relevant information from the prior clause before the rest of the current clause is encoded or integrated with that prior clause. This is not an example of explicit anaphoric reference (in the absence of an explicit antecedent); however, it is similar to implicit or "indirect" anaphoric reference (Carpenter \& Just, 1977b; Clark, 1977; Haviland \& Clark, 1974; Singer, 1979), since the first clause establishes a schema that in turn, allows the reference to be disambiguated.

An additional important issue concerns the initial set of potential antecedents for a pronoun. We have argued that, initially, the potential antecedents of an anaphoric reference may be restricted to concepts that 
are highly available. In addition, semantic constraints imposed by the pronoun may limit retrieval; in the case of singular personal pronouns, only persons of the appropriate gender may be accessed. At least two projects (Caramazza et al., 1977; Springston, 1975, Experiments 7 and 8 ) have produced relevant data that might appear to contradict this proposal. These studies examined the interaction of gender constraints with verb-induced biases in pronoun assignment. Both of these projects employed two-clause sentences, with proper name subjects and objects in the first clause and a pronoun in the second clause. In these studies, the verbs in the sentence tended to bias pronoun assignment toward either the first-clause subject or object. The complete second clause ultimately determined assignment, but processing was slowed if ultimate assignment conflicted with the initial verb-induced bias. The important point here is that verb bias influenced processing time even when gender constraints imposed by the pronoun should have been sufficient to disambiguate the reference. This might suggest that readers actively consider potential antecedents that mismatch gender constraints imposed by the pronouns. However, the processing time measured in both studies included both the time to read the sentence and the time to identify the intended antecedent. As a result, these data do not provide direct evidence that gender-mismatched names were retrieved and evaluated in the assignment process. Instead, verb bias may be influencing clause integration time rather than pronoun assignment.

Chang (1980), on the other hand, has provided evidence that gender-mismatched names are not retrieved in pronoun assignment. As described earlier, Chang conducted a probe recognition study similar to the present ones, except that the proper names in the first clause differed in gender (e.g., "Bill and Mary went to the store, and Bill/he bought a quart of milk"). But in Chang's study, response time to a nonantecedent probe ("Mary") was constant across the proper name and pronoun conditions. That is, a masculine (feminine) pronoun did not seem to lead to retrieval of a feminine (masculine) proper name. Chang's results suggest that the set of potential antecedents would be limited to highly available concepts that match the semantic constraints of the pronoun. More correctly, potential antecedents are limited to concepts that do not mismatch semantic constraints, since a pronoun may provide previously unknown information (e.g., "Since the professor had a flat tire, he was late for class"). Metaphorical usage of pronouns (e.g., "she" for ships, "he" or "she" for storms) might be considered to violate this rule, but these are perhaps better thought of as learned homonyms of the pronouns, since he/she cannot be used indiscriminately in this fashion (e.g., "John bumped into the bicycle and she fell down").

If potential antecedents are retrieved when a pronoun is encountered and only one potential antecedent is actually found, then that concept may be tentatively accepted as the intended antecedent. This assignment would, in effect, be double-checked in the integration process, since ultimately, the antecedent must match not only pronominal semantic constraints but also conditions imposed by the clause in which it is referenced. If we read "Bill pointed the gun at Mary, but she did not pull the trigger," we may initially assign "Mary" as the antecedent of "she." Ultimately, however, we recognize that the antecedent of "she" must be holding a gun, and there is either an error in the sentence or something wrong with our conception of the situation. Thus, preliminary assignment does not preclude a final checking based on clause integration, but such preliminary assignment could facilitate comprehension and integration of the pronoun-bearing clause.

\section{REFERENCES}

Anderson, J. R., \& Paulson, R. Representation and retention of verbatim information. Journal of Verbal Learning and Verbal Behavior, 1977, 16, 439-451.

Begg, I., \& Wickelaren, W. A. Retention functions for syntactic and lexical vs. semantic information in sentence recognition memory. Memory \& Cognition, 1974, 2, 353-359.

Burrows, D., \& OradA, R. Parallel scanning of physical and category information. Memory \& Cognition, 1976, 4, 31-35.

Caramazza, A., Grober, E., Garvey, C., \& Yates, J. Comprehension of anaphoric pronouns. Journal of Verbal Learning and Verbal Behavior, 1977, 16, 601-609.

Carpenter, P. A., \& Just, M. A. Integrative processes in comprehension. In D. LaBerge \& S. J. Samuels (Eds.), Basic processes in reading: Perception and comprehension. Hillsdale, N.J: Erlbaum, 1977. (a)

Carpenter, P. A., \& Just, M. A. Reading comprehension as eyes see it. In M. A. Just \& P. A. Carpenter (Eds.), Cognitive processes in comprehension. Hillsdale, N. J: Erlbaum, 1977. (b)

ChAFE, W. L. Meaning and the structure of language. Chicago: University of Chicago Press, 1970.

Chang, F. R. Active memory processes in visual sentence comprehension: Clause effects and pronominal reference. Memory \& Cognition, 1980, 8, 58-64.

ClARK, H. H. The language-as-fixed-effect fallacy: A critique of language statistics in psychological research. Journal of Verbal Learning and Verbal Behavior, 1973, 12, 335-359.

Clark, H. H. Inferences in comprehension. In D. LaBerge \& S. J. Samuels (Eds.), Basic processes in reading: Perception and comprehension. Hillsdale, N. J.: Erlbaum, 1977.

Clark, H. H., \& Sengul, C. J. In search of referents for nouns and pronouns. Memory \& Cognition, 1979, 7, 35-41.

Garvey, C., Caramazza, A., \& Yates, J. Factors influencing assignment of pronoun antecedents. Cognition, 1976, 3, 227-243.

Haviland, S. E., \& ClakK, H. H. What's new? Acquiring new information as a process in comprehension. Journal of Verbal Learning and Verbal Behavior, 1974, 13, 512-521.

Hirst, W., \& BriLl, G. A. Contextual aspects of pronoun assignment. Journal of Verbal Learning and Verbal Behavior, 1980, 19, 168-175.

Hupet, M., \& Le Bouedec, B. The given-new contract and the constructive aspect of memory for ideas. Journal of Verbal Learning and Verbal Behavior, 1977, 16, 69-75.

Lescold, A. M., Roth, S. F., \& Cuntis, M. E. Foregrounding effects in discourse comprehension. Journal of Verbal Learning and Verbal Behavior, 1979, 18, 291-308.

McKoon, G., \& Ratchiff, R. Priming in episodic and semantic 
memory. Journal of Verbal Learning and Verbal Behavior, $1979,18,463-480$.

McKoon, G., \& RAtclifr, R. The comprehension processes and memory structures involved in anaphoric reference. Journal of Verbal Learning and Verbal Behavior, 1980, 19, 668-682. (a)

McKoon, G., \& Ratcliff, R. Priming in item recognition: The organization of propositions in memory for text. Journal of Verbal Learning and Verbal Behavior, 1980, 19, 369-386. (b)

McKoon, G., \& RATCLIFF, R. The comprehension processes and memory structures involved in instrumental inference. Journal of Verbal Learning and Verbal Behavior, 1981, 20, 671-682.

RAtcliff, R., \& McKoon, G. Priming in item recognition: Evidence for the propositional structure of sentences. Journal of Verbal Learning and Verbal Behavior, 1978, 17, 403-417.

SACHS, J. S. Recognition memory for syntactic and semantic aspects of connected discourse. Perception \& Psychophysics, $1967,2,437-442$.

SaCHs, J. S. Memory in reading and listening to discourse. Memory \& Cognition, 1974, 2, 95-100.

Sanford, A. J., \& Garrod, S. C. Understanding written language. New York: Wiley, 1981.

Sheldon, A. The role of parallel function in the acquisition of relative clauses in English. Journal of Verbal Learning and Verbal Behavior, 1974, 13, 272-281.

Singer, M. Processes of inference during sentence encoding. Memory \& Cognition, 1979, 7, 192-200.

SPringston, F. J. Some cognitive aspects of presupposed coreferential anaphora. Unpublished doctoral dissertation, Stanford University, 1975.

Tyler, L. K., \& Marslen-Wilson, W. D. The on-line effects of semantic context on syntactic processing. Journal of Verbal Learning and Verbal Behavior, 1977, 16, 683-692.

\section{APPENDIX A: \\ THE TEST STIMULI USED IN EXPERIMENT 1}

Larry accidentally scratched Stuart with a knife and Iarry apologized for it

Wanda shot at the target that Joyce had missed and Wanda hit it.

Russell saw Bill standing on the river bank and Russel waved from his canoe.

Malcolm received a chain letter from Pete but Malcolm did not continue the chain.

Rachel tried to catch Sally but Rachel was not able to do it. Bernie saw Glen steal a car but Bernie did not tell the police.

Keith read a story to Arnold but Keith started to get hoarse before long.

Debbie would not accept a check from Brenda but Debbie did accept a credit card.

Walter went to visit Jeff in the hospital and Walter brought some flowers.

Sandra lost to Amy in tennis and Sandra accepted defeat gracefully.

Bob threw a custard pie at Vince but Bob missed.

Ellen aimed a pistol at Harriet but Ellen did not pull the trigger.

Cheryl went to visit Maureen and then Cheryl went home after awhile.

Janet was invited to a party by Marcia but Janet did not accept.

Gary was interviewed by Marvin but Gary would not answer many questions.

Scott stole the basketball from Warren and then Scott sank a jumpshot.

Karen poured a drink for Emily and then Karen put the bottle down.

Frank saw that Dennis was stuck and Frank ran to get help.
Janice handed a spoon to Barbara but Janice took it back right away.

Adam started writing a story about Barry but Adam never finished it.

Carla broke her leg playing with Pam and afterwards Carla hobbled around on crutches.

Sharon watched Bonnic on television for awhile and then Sharon changed the channel.

Mike inherited a large fortune from Gerald and Mike spent it foolishly.

Gloria listened to Jill give an explanation but Gloria could not understand it.

Beverly sat down to watch Kate jogging but then Beverly got up and left

Timothy tried to amuse Doug with a joke but Timothy forgot the punchline.

Richard tricd to cook a nice meal for Oscar but Richard burned the peas.

Danny promised to go visit Nelson but Danny never did.

lrene watched Doris bouncing on a trampoline and then Irene climbed on the trampoline too.

Ted kidnapped Randolph and then Ted sent out a ransom note.

Lisa watched Margaret act in a play and Lisa applauded wildly at the final curtian.

Shirley wanted to call Priscilla but Shirley could not find a tclephone.

Nick was playing his guitar for Arthur but then Nick broke a string.

Ross stood up until Neil brought a chair and then Ross sat down on it.

Harry took over laundry chores from Ben and Harry did a much better job.

Elaine heard a rumor that Donna murdered an old man but Elaine did not believe it.

Andrew escorted John to the doctor's office and then Andrew waited out side.

Polly strongly disapproved of what Louise did and Polly said so.

Heather saw Sue fall off the water skis and Heather quickly turned the boat around.

Patrick made a cup of coffee for Craig but Patrick neglected to offer cream or sugar.

Linda gave a long lecture to Mildred and Linda covered many topics.

Don was searching for a recipe to give Hank but Don could not find it

Steve locked Woody up in a jail cell and then Steve went home.

Lillian saw that Molly had a flat tire and Lillian stopped to offer help

Elizabeth was going to play a trick on Ruth but then Elizabeth decided not to.

Wayne loaned a pen to Harold but Wayne wanted it back before long.

Nancy tried to repair a clock for Phyllis and Nancy did a good job.

Eric inspected the money he got from George and Eric decided it was counterfeit.

Cindy was drawing a picture of Marily $n$ but Cindy paused to sharpen a pencil.

Karl heard that Howard was sick and Karl went out to buy a get well card.

Jenny borrowed a book from Alice and then Jenny never gave it back.

Lucy described the city to Joanne but Lucy did not mention the new museum.

Betty watched Claire take off at the airport and then Betty drove home. 
Henry was being tickled by Alex but Henry managed not to laugh.

Jane started writing a letter to Becky but then Jane tore it up.

Ken saw Harvey dozing in the hammock and Ken decided not to mow the lawn.

Wendy modeled her new coat for Diane and then Wendy took it off.

Carolyn made sure that Ginny was asleep and then Carolyn tiptoed out the door.

Matthew saw a picture of Bill in a magazine and Matthew clipped it out.

David was knocked down by Kevin and David got up slowly.

Christine wanted to go visit Laura but Christine got lost on the way.

Helen rescued Valerie in the ocean and as a result Helen received an award for bravery.

Philip was punched by Ernie and the next day Philip had a bruise.

Greg found a notebook that belonged to Rusty and Greg returned it.

Cathy bought a car from Jean and Cathy was pleased with its performance.

Vivian got the radio out that Tammy had given her and Vivian turned on some music.

Allan was singing a song for Ray but Allan forgot the words partway through.

Tom made a shirt for Roy but Tom neglected to put buttons on it.

Chuck received a present from Martin but Chuck didn't like it very much.

Chester wrapped a gift for Mark and then Chester hid it in the closet.

Angela went fishing in a boat she borrowed from Trudy but Angela did not catch anything.

Connie was knitting a scarf for Rosemary but Connie ran out of yarn before finishing.

\section{APPENDIX B :}

\section{THE TEST STIMULI USED IN EXPERIMENTS 2 AND 3}

Karen tried to beat Polly in chess but Polly always managed to win.

Andy saved a place for Keith but Keith never showed up. Steve sent Russell to the pharmacy but Russell got lost on the way.

Mildred mailed a letter to Jane but Jane did not reply.

Janice gave Sharon some advice but Sharon ignored it.

Scott pushed Peter to the ground and Peter got up slowly.

Wendy found out that Anne was sick but Anne got better quickly.

Paul spilled a drink on Dennis and Dennis had to go change his clothes.

Sandra expected Lucy to arrive on the train but Lucy was not on it.

Bonnie passed the basketball to Claire and Claire sank a jumpshot.

Jeff accused Stanley of robbery and Stanley was convicted in court.

Walter guarded Frank closely but Frank escaped before long.
Cheryl wanted to take a snapshot of Brenda but Brenda would not stand still.

Barry took a sandwich that belonged to Stuart and Stuart wanted it back.

Amy called Susan on the telephone and Susan answered after a few rings.

Brad accidentally scratched Ricky with a knife and Ricky started to bleed.

Chuck tried to amuse Alex with a joke but Alex did not laugh at it.

Donna gave a long lecture to Shirley and Shirley listened to it patiently.

Tammy asked Laura to pick a card and Laura drew the ace of diamonds.

Bill sent Raymond to the market and Raymond came back with lots of groceries.

Irene tried to catch Rita but Rita got away.

Gary gave Kevin a lot of money and Kevin spent it foolishly. Gloria invited Sally to a party but Sally did not accept.

Nancy convinced Maureen to apply to law school and Maureen was accepted.

Connie tried to tickle Elaine but Elaine managed not to laugh.

Glenn locked Martin in the closet and Martin pounded on the door to get out.

Philip threw a custard pie at Jim and Jim was hit in the face.

Helen thought Christie was working in the garden but Christie had gone to town instead.

Kenny pitched the ball to Tom and Tom hit it into leftfield.

Valerie looked all over the house for Lisa but Lisa was hiding in the attic.

David wanted Tony to play handball and Tony agreed to do it.

Ted mailed a package to Woody and Woody received it before long.

Neil blamed Howard for the accident but Howard was really not at fault.

Beverly told Doris to leave but Doris refused to go.

Janet asked Cindy to play golf but Cindy already had other plans.

Priscilla gave Kathy directions to the lake and Kathy had no trouble following them.

John challenged Wally to a wrestling match and Wally eagerly accepted.

Benjamin went to visit Roy but Roy was away on vacation. Debbie tied Lillian to a chair but Lillian was able to get loose.

Karl loaned some tools to Danny and Danny returned them a week later.

Marsha tried to interview Jenny but Jenny would not answer any questions.

Eric thought Warren might hit the parked car but Warren swerved just in time.

Vince punched Larry and the next day Larry had a black eye.

Linda predicted that Majorie would lose the race but Marjorie won easily.

Greg called to Mark but Mark did not hear.

Joe passed the football to Doug and Doug caught it in the end zone.

Jill waited in the restaurant for Harriet and Harriet finally arrived.

Diane sent a check to Becky and Becky cashed it right away. 